\title{
MODELS OF SPEECH PRODUCTION *
}

Chin-W. Kim

University of Illinois

\section{Introduction}

The most dominant issue among phoneticians in recent years has been the question of the model of speech production, in particular the size or the unit of speech encoding (cf. Fromkin, 1965, 1966, 1968, 1971; Kim, 1971b; Kozhevnikov and Chistovich, 1965; Ladefoged, 1967; MacKay, 1970; MacNeilage, 1970; Ohala, 1970; Öhman, 1967; Tatham, 1971; Tatham and Morton, 1969; Whitaker, 1970; and Wickelgren, 1969).

Ever since Sapir (1933) advanced the notion of the "psychological reality of phonemes", the concept of a phoneme has been accepted as something real which has an invarient correlate at some level. And needless to say, the concept of the phoneme was the cornerstone of structural linguistics. The notion of phonemic reality was strengthened by the supposedly superior alphabetized writing systems of the Western world. If the language user writes two different sounds with one and the same symbol, he must regard them as mentally the same, so goes the argument. Actually, this notion is not so unchallengeable as it might seem. For one thing, I am not at all sure if awareness of this sameness is equally strong in speakers of languages which do not have writing systems. Secondly, the alphabetic system is not the only writing system that the human civilization has known. As a matter of fact, the earliest writing systems were syllabic, and many languages like Arabic, Chinese, and Japanese still have syllabic writing systems, and even though they have been looked upon as something less economical and less optimum, I think they should be given more merit for the reasons that will become clear shortly.

It is sufficient at this point to cite one interesting experiment. In a recent article in Science, Rozen et al (1971) reported an experiment which showed that American children with reading problems chould easily learn to read English when represented by Chinese characters. Eight to nine year old experimental children were chosen for their reading deficiency. "They had difficulty in identifying words by initial or final sounds and in combining a sequence of letters into a known English word", and "were unable to read reliably a set of rhyming words (cat, fat, mat, sat) after being given the pronunciation of at." (p. 1264) Yet after a few hours of training in which they learned Chinese characters representing some English words, they could read quite easily sentences made of these characters (e.g. 父買黑真 "father bought a black car"). The authors hypothesize that reading disability in the case of sentences written in English alphabet is largely accountable in terms of the highly abstract nature of the phoneme, while facility in the case of sentences repre(1971), $16-128$ 
sented with Chinese characters is on the account of the fact that Chinese characters map into speech at the level of words rather than of phonemes or alphabetic letters as is the case in English, and propose the unit of syllable as the most suitable vehicle for teaching reading. The merit of syllable will become more apparent in the course of this paper.

\section{Units in Production of Speech}

What is the unit of speech production? It would be ideally economical if our brain stored separate instructions for each phoneme and generated them in the order of sequence in a phonemic string. Note, for example, the following traditional account of the process of speech production:

We shall assume that the speaker has stored in his memory a table of all the phonemes and their actualizations. This table lists the different yocal tract configurations or motor gestures that are associated with each phoneme and the conditions under which each is to be used. In producing the utterance the speaker looks up, as it were, in the table the individual phonemes and then instructs his vocal tract to assume in succession the configurations or gestures corresponding to the phonemes. (Halle and Stevens, 1964, p. 605)

This simple view, however, runs into many difficulties. Spectrograms do not show invariant acoustic correlates. Attempts to construct an automatic speech recognition device (e.g., a machine that will take speech as input and produce a print-out of its phonemic instantiation as output) has failed despite years of efforts. Speech synthesizers that "look up" phonemic tables produce all but natural speech.

The search for phonemic invariance at the motor level through electromyographic studies (e.g., Fromkin, 1965; Harris et al, 1965; Lubker and Parris, 1970; MacNeilage, 1963; MacNeilage and Sholes, 1964, etc.) has not presented cause for more optimism. One then began to speculate that the unit of speech encoding may have a different magnitude than the size of a phoneme, and there are some indications that it is perhaps something larger than the phoneme size.

This paper is a review of models of speech production. For ease of exposition, I will polarize the two alternative models, perhaps more than it is warranted. Later I will examine some phenomena in speech that seem to favor one model over the other.

The two opposing models may be given the descriptive names: the "saw-tooth" model and the "comb" model (see diagram below). The saw-tooth model assumes that speech generation is nothing but a concatenation of a string of phonemes, each phoneme receiving a separate instruction from the brain, and functioning as a stimulus for eliciting the next phoneme in the string, in a manner that psychologists call a chain-association. In this model, the chain forms a closed-loop, as a phoneme is integrally linked to the next segment as the feedback to the latter's realization, much as a guided missile determines its flight path upon receiving information about its target's direction, speed, etc. On the other 
1and, the comb model of speech production assumes that something larger than a phoneme, say a syllable or a word, forms an instructional and operational unit at the neuro-muscular level. That is, it is the syllable or word blocks, not individual phonemes, that receive spearate brain instructions. In this view, speech is a serial behavior in the sense of Lashley (1951), like skilled typing or piano playing in which the performer's hands receive preprogrammed instructions of the size of a word or a measure from the brain. This model then is open-looped, much like a traffic light system that does not take the actual traffic volume into account in changing signals once the time pattern is built into the system.

One can diagram the two alternative views in the following way:

The "Sawtooth" Model

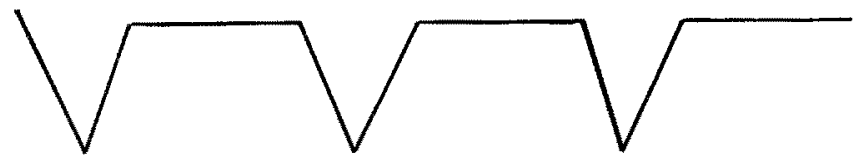

a - beginning of a neural command

$b$ - beginning of the movement

$c$ - moment of arrival of afferent impulsation about $b$

$x$ - time interval for conduction of neural command

$y$ - time interval for conduction of feedback signal

$z$ - latent period until the next neural command

(adapted from Kozhevnikov and Chistovich, 1966, p. 94)

\section{The "Comb" Model}

A

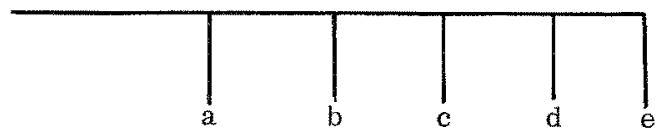

A - simultaneous instruction

a-e - sequential realization

(adapted from Ohala, 1970, p. 121)

Major arguments for favoring the comb model are:

(1) In running speech, phonemes are not segmentable into discrete units but overlap in their articulation.

(2) There is not enough time for a round-trip transit of nerve impulses. Human motor responses to sensory stimuli take as long as $1 / 8$ second.

(3) There are differences in nerve impulse conduction times, among articulator muscles, of up to $30 \mathrm{msec}$ (Lenneberg, 1967, p. 96). A single stimulus cannot trigger a complex of commands which have to be temporally staggered. 
Proponents of the phoneme theory counterargue that the lack of invariants is due to such factors as the mechanical constraints inherent in the peripheral vocal apparatus, limitations in the response capabilities of the muscular system, and overlapping in time of the effects of successive phoneme commands. As for (2) above, Ohala (1970) argued, à la Fairbanks (1954), that it is not necessary that a gesture be 100 percent completed before afferent information on the progress of the gesture is reported to the brain. Afferent signals are probably continuously sent to the brain which is capable of predicting on the basis of initial preliminary information. This is plausible, Ohala continues, because as speech movements become more automatic and more removed from the conscious control, the articulation becomes more reflexive, which requires shorter latencies. Ohala also counterargued the point (3) above by saying that laryngeal synchronization is not precise in voice onset time in aspiration and voicing. Furthermore, Ohala's reconstruction of conduction time differences between oro-facial nerves and laryngeal nerves showed only a difference of 9 msec. which Ohala doubts will present any great problem for the kind of precise coordination believed to be required by Lenneberg.

Strong support for the closed-loop model came recently from Wickelgren (1969) who argued that Lashley's rejection of the associative-chain model was premature in that one needs to distinguish non-creative serial behavior from creative serial behavior and that Lashley's objection applies only to the latter, but not to the former to which word production belongs. Wickelgren attempts to rescue the associative-chain hypothesis by proposing "context-sensitive" associative-chain theory which assumes that serial order is encoded by means of associations between "context-sensitive elementary motor responses" (EMR). In speech, this means that a word such as stop is assumed to be coded allophonically as $\left[\#_{t}\right]$ ( $[s]$ in the context of $\not$ - $[t]),\left[_{s} t\right],\left[c_{t}^{o}\right]$, and $\left[p_{0}\right]$. In this model the basic units of production would be context-sensitive allophones, and serial ordering of these EMR's would be achieved, as Whitaker $(1970$, p. 3) put it, by interlocking the preceding and following contexts in puzzle fashion. Since stress, pitch, and durational differences in otherwise identical contexts constitute independent EMR's, it turns out that one needs to store about $10^{4}$ to $10^{6} \mathrm{EMR}$ 's for speech production. Wickelgren claims that this is not a problem because the human cortex contains about $10^{10}$ neurons. Regardless of the counter-intuitive nature of this necessity for such an enormous cerebral storage and retrieval capacity, I think the numerology here is quite meaningless. There is no evidence whatsoever that each neuron is associated with a specific allophone or an EMR. Available evidence is rather that a complex network of neurons behaves in a multiply integrated way, and unless some specific relationships between allophones and neurons are observed, a claim that the number of allophones does not begin to exhaust the number of neurons in the brain is pointless. 
Wickelgren's paper occasioned a criticism by MacKay (1970) who, citing examples from German and English spoonerisms, argued that Wickelgren's model would fail. Specifically, MacKay assumed that since association in the chain model is unidirectional, it would predict that reversed segments in spoonerisms would occur much more frequently following repeated segments, i.e., ABCBDA $\rightarrow$ ABDBCA, e.g., Cavalerie $\rightarrow$ Calaverie, and that positions of reversals would be random as long as the reversed segments share similar contexts in the chain. But MacKay found that repeated segments followed the reversed segments as often as they preceded them, e.g., Wasserflasche $\rightarrow$ Flasserwasche, and that, as others have also observed (Boomer and Laver, 1968; Fromkin, 1971), reversed segments occur only in the same position within the syllable, i.e., the switching occurs only between two syllable-initial segments, between two syllable nuclei, or between two syllablefinal segment.

In a pilot study, Tatham and Morton (1970) tested Wickelgren's model by trying to detect any EMR differences between two [k]'s in [aku], [uka] and [iku], [uki]. They reasoned that if Wickelgren was right, ENR for $[k]$ in the former set should be different from that in the latter set; in particular, the muscle contraction for lip-rounding in the former $[\mathrm{k}]$ would be greater and longer than in the latter case because [a] is neutral to lip-rounding, while $[i]$ requires lip-spreading which is antagonistic to lip-rounding. Since EMR's are context-sensitive, the two $[k]^{\prime} s$ would constitute two different EMR's and therefore would show different EMG patterns. But the result was negative, i.e., EMG activity in $\left[k_{a}\right]$ was not different from that in $\left[k_{i}\right]$. Since there are nonetheless differences in spatial configurations of the lips during the two $[k]^{\prime} s$, Tatham and Morton's conclusion was that "[ $\left.{ }_{a} k_{u}\right]$ and $\left[k_{i} k_{u}\right]$ exist after coarticulation, but only $[k]$ exists before coarticulation" (pp. 121-122).

MacKay's criticism of Wickelgren was soon rebutted by Whitaker (1970) who assumed that Wickelgren could have argued that MacKay's hypotheses about reversals in spoonerisms are not relevant to associative-chain theory because it is after the error has been made that the correct group of EMR's is assembled. Thus, all examples that Mackay cited agains Wickelgren could no longer be damaging, since EMR's are activated after their erroneous ordering has been established. This assumption, Whitaker says, is borne out well by the fact that regardless of the cause of error, the error output is still an admissible sequence in the language obeying all the phonological constraints. (I have noted, however, the following exceptions: comb $\rightarrow$ nogwp nowp (Hockett, 1967, p. 915, fn. 11 ) stick shift $\rightarrow \underline{\text { shtick }}$ sift (Fromkin, $\perp 971$, p. 32).) Whitaker gives a hypothetical example of a spoonerism which would crucially bear on the issue. That is, if a loud spanking spoonerized into a poud slank$\underline{i n g}$, the model would predict that the allophone of $\mathrm{g}$ would be articulated as a word-initial 
aspirated $\left[\mathrm{p}^{\mathrm{h}}\right]$, not as a post-s unaspirated $[\mathrm{p}]$. If any residues of the originally intended context remained in the realized output, the model would be disconfirmed.

Mackay, Ohala, and Whitaker propose a model of language programming in which an entire phrase is simultaneously displayed in a "buffer" zone, then is read off or scanned in a unidrectional fashion. That is, speech units are put into some kind of a "hopper" (Ohala, 1970 , p. 133) where they are entered in a particular order-the order in which they will be "fed" to the appropriate muscles. In Whitaker's words, "the phonological output of the grammer is displayed in a buffer and the tracking mechanism tracks this display by activating the requisite vocal tract command sets".

Kozhevnikov and Chistovich's (1965) view is somewhat eclectic, eclectic in the sense that their model uses both the open-Ioop mechanisms. They hypothesize that what makes the string of segments in a syllable be realized in a serial order is not a separate and direct instruction for each segment from the speech center, nor a proprioceptive impulsation (sensation of tension in muscles) occurring upon the movements such that stimulation for the following movement is subliminal, which becomes above the threshold value to cause an external effect when given an additional push created by the impulsation occurring upon articulation of the preceding segment.

MacNeilage (1970) is a bit more specific about the reflex mechanism. He borrows Hebb's (1949) notion of motor equivalence which is to say that the motor system is controlled by internal specifications of certain spatial targets so as to achieve a single result, e.g., reaching for a door-knob, a tennis player reaching for the ball hit by the opponent, etc. In MacNeilage's model, the open-loop component emits a context-independent command for an articulator to reach a certain position and closed-loop control circuits constantly sample the mechanical state of the articulator and adjust the command accordingly (speaking with a cigarette or a pipe in one's mouth provides a good example of such adjustment). MacNeilage speculates that this feedback loop is controlled by the gamma motor system.

\section{Syllable as a Candidate}

Having so far discussed in some detail a few models of speech production, I will now turn to an examination of some phenomena in speech that seem to indicate the syllable as a unit of linguistic performance. While the examples do not constitute direct neurophysiological evidence, I think that their implications are fairly and attractively strong. The basis of this optimism is the assumption that, while it is not absolutely required that neurophysiological matrix be mappable into behavioral matrix in a strict one-to-one fashion, there is enough projection onto behavior so that its examination can lead to reasonable assumptions about the underlying mechanisms. The rationale is hardly needed. A physicist's assumption of atomic structures, Einstein's special theory of relativity, Percival Lowell's prediction 
of the existence of Pluto on the basis of his observation of the anomalous motion of Uranus, internal reconstruction in historical linguistics, etc. all bear testimony to reasonableness of the assumption.

Earlier, I expressed a doubt of psychological reality of phonemes in naive subjects. Since Sapir's 1933 paper has been a powerful and influential one, it is worth reexamining some of his examples that purport to show the psychological reality of phonemes. His first example had to do with his Southern Paiute interpreter named Tony writing his native word $[\mathrm{pa} \cdot \beta \mathrm{a}]$. Tony wrote, "pa*, pause, pa"." This "astonished" Sapir, because Tony was not "hearing" phonetically but phonemically, for in Southern Paiute, prevocalic $/ p, t, k /$ are spirantized, becoming allophonically $[\beta, r, \gamma]$ respectively. Since Tony did not write intervocalic $/ p /$ as $[\beta]$ as it was pronounced but as $[p]$, this constituted to Sapir the evidence of a psychological reality of phonemes. But what is "astonishing" is not so much the fact that 'Tony wrote the second syllable as pa' as the fact that he broke the phrase into two syllables: pa., pause, pa'. Given the fact that there was a pause before the second syllable and given the fact that a spirant does not oceur initially in Southern Paiute, Tony had no choice but to write pa". I will examine another example from Sapir in a later section.

An indication that people are not awaxe of individual segments as much as the alphabetic writing system implies comes from an experiment with reversal of words. In an informal test, I once prepared a list of polysyllabic sequences which contained actual English and Swahili words, and asked the subjects to reverse the words (by speaking, not by writing). In nearly all cases of successful attempts, the words were reversed in terms of syllable sequences, not in terms of segmental sequences (this after practicing with a few monosyllabic words such as cat, Tim, bat, etc.) For example, hospital would come out as tal-pihos (not latipsoh), Timbuktu as tu-buk-tim, kikapu, "basket", as pu-ka-ki, samaki, "fish", as ki-ma-sa (not as ikamas), etc. This shows that people are not as much aware of segmental sequences as syllable sequences.

A similar result has been obtained from perceptual experiments which have shown that people could not identify the temporal ordering of setments (Ladefoged, 1967; Thomas et al, 1970). For example, when unfamiliar nonsense segments were presented, listeners could easily differentiate between complex stimuli which differed in the order of their components. But they differentiated the stimuli as wholes and could not tell the relative times of arrival of the component parts. That is, the stimuli which differed only in the order of their components were perceived as being different simply in overall quality. An experiment with localization of a click showed the same negative results, suggesting that listeners have difficulty in determining the physical order of arrival of individual items, and therefore that immediate perception is perhaps in terms of larger units than phoneme. 
Another indication that the syllable is the minimal unit of production is found in children's babblings which are emitted always in terms of the CV type, e.g., ma, ma, ma, $[\mathrm{ma}, \mathrm{ma}, \mathrm{ma}],[\mathrm{da}, \mathrm{da}, \mathrm{da}]$, or $[\mathrm{ka}, \mathrm{ka}, \mathrm{ka}]$. "They do not babble in any way that indicates awareness or control of units smaller than a syllable." (Ladefoged, 1967, p. 148) Thus, even when they have mastered the above phrases, such independent and arbitrary sequences as [madaka], [akadam], [amkad], etc. do not occur.

Another impressionistic evidence of syllable is stuttering and false starts. It has been observed that stutterers stutter in terms of syllables (Taylor, 1966), and that in false starts one cannot correct oneself before the completion of at least the first syllable of an utterance, even though the speaker has come to be aware of the mistake before or during the first segment of the utterance. (cf. "Such errors are practically never corrected until a whole syllable at least has been emitted." Fry, 1964, p. 219) An argument can be made to the effect that if the neural commands were sent out phoneme by phoneme, one should be able to stop at any segment in the utterance, but if the unit of neural commands is syllable, then one would have to complete the motor execution of that syllable once the command has been set out, i.e., there would be no way to retrieve it in the middle of the syllable. The phenomenon may be likened to a pitcher's throw or a golfer's swing. During the final windup before the ball leaves the pitcher's hand, the pitcher may realize that the ball is going to be a wild pitch, and the golfer may realize during his final swing before his club hits the ball that it is going to be short of the green. Despite this realization, however, he is unable to change the pattern of the swing, as neuronal commands for that final swing have already been fired, and once fired, they must be executed. Any any one who has typed is probably familiar with the sensation that he has often experienced when he "had to" hit a wrong key even though the realization that it was a wrong one had come prior to the downward movement.

A more relevant phenomenon is a temporal overlap between articulations of two or more phonemes. In such words as two, who, coo, one can easily detect the lip-rounding beginning with or before the initial consonant, not after (compare these words with tea, he, key). Daniloff and Moll (1968) found that coarticulation of rounding can begin as early as four consonants before it is segmentally due (e.g., in such words as since true and construe, the lip-rounding for $\underline{\mathrm{u}}$ was observed to start at $\underline{n}$ ). One can argue that if there were a separate and independent neural command for each phoneme and if these commands were generated sequentially, how is it possible that a part of articulation of the following phoneme is executed during the articulation of the preceding phoneme? Doesn't this suggest that our effector organs already possess information concerning the second segment at the same time as the articulation of the first segment is being accomplished? It was in this vein that 
Kozhevnikov and Chistovich (1965) hypothesized that the minimal unit of a motor command is a syllable, not a phoneme, and accordingly, that segments within a syllable receive a simultaneous package of instructions for articulation.

One can of course argue that as early as 1951, Lashley theorized that certain behaviors involving rapid serial movements, e.g., piano playing, galloping, speaking, etc. must be centrally programmed rather than peripherally organized. But Lashley was never specific about the mechanism in speech production, and phonemic realism in structural linguistics was so strong that Lashley's hypothesis went largly ignored and untested. Thus, most early EMG studies were primarily occupied with finding motor invariants of phonemes, and the so-called associative-chain model dominated the thinking of behavioral and physiological psychologists.

Another important finding of Kozhevnikov and Chistovich was that in different rates of speech, syllable was the smallest unit that was compressed or lengthened in equal proportion to the total length of time of the uttexance. Compression ratio of individual segments was not in the same proportion to that of the larger units. Since it is reasonable to assume that the durational relationship in the case of the varying tempo of speech is such that the sum of the variances of the component parts should be equal to the variance of the total utterance, the smallest component that shows just this kind of relationship would be considered to be a programming unit in temporal organization of the utterance. On the other hand, one would expect a durational interaction among subparts of the unit in such a way as to compensate or complement each other in order to maintain the specified average value. This is what Kozhevnikov and Chistovich found with respect to the syllable (see also Lindblom, 1968).

Lehiste (1970) obtained a similar result by examining temporal organization of several English words such as stead, stay, stayed, steady, etc. She found that there was indeed a temporal compensation between component segments in these words. For example, in various pronumciations of the word steady, there was a negative correlation between the two vowels in such a way that if one vowel was longer, the other was proportionately shorter, thus all tokens maintaining the same average duration. What is more surprising was the fact that the words stead and staid had the same total duration, although the vowel in stead is intrinsically shorter than that in staid. A temporal compensation was made by longer durations of consonants. This study shows that the unit of articulatory programming is certainly larger than the size of a segment, and makes it difficult to believe that articulation is merely a series of tacking-on of segments (if this were the case, a word in isolation and the same word appearing as a stem in a derivational form would have the same duration, and the latter word would be longer than the former just by the amount of the number of segments 
in the suffix), and provides a rather strong argument against the view that speech production is a phoneme-by-phoneme Markovian process.

The rhythm in speech also appears to behave in terms of units of syllable size. Thus, iambic pentameter means that there are five sets of paired syllables in a line, e.g.,

And ALL the AIR a SOLemn STILLness HOLDS.

(From Thomas Gray's Eligy. Capital letters indicate stressed syllables.) Although the role of rhythm in prose language is not comparable to that in poetry, it should not be minimized, since, although not always regular, it definitely has tendency to maintain iambic rhythmicity. Note the stress contour in such words as ARtifIciALiTY, DIFfeRENtiAtion, OPporTUniTY, etc. A good example of the alternating stress pattern is found in Finnish where the stress falls regularly on odd number syllables, e.g., TIEttäMÄttöMYYdesTAni "about my ignorance". The underlying current of rhythm is so strong that when rhythm is grossly violated languages seem to have rules whose sole function is to readjust the stress pattern so as to maintain the rhythmicity. Thus, English has rules like Stress Adjustment and Auxiliary Reduction (cf. Chomsky and Halle, 1968, Chapter 3) that produce rhythmic contours. For example, to derive soLIDity from SOLid+ity, the original primary stress must be weakened to tertiary as the new primary stress is assigned on the next syllable in the noun form. To give another example, in Tunica (an AmerIndian language in Louisiana) TAkoMEli "a species of tree" is derived from ta "determiner" + KO "tree" + MEli "black", and the underlying form of TIyahPAni "she was hungry, it is said" is $\underline{\text { ti }}+\underline{\text { YAHpa }}+$ Ani. It has also been observed that in English a lexical stress can shift to conform with the rhythmic stress, e.g. , JUST fourTEEN vs. FOURteen SHILLings; QUITE UnKNOWN vs. an UNknown LAND (Jones, 1959, p. 253).

It hardly needs a mention that the domain of stress is also a syllable, not just a vowel or a syllable nucleus. Stress just does not shift to an immediately neighboring segment but to the preceding or the next syllable, and not only does the vowel manifest the stress, but so do consonants in the same syllable by being aspirated, by having a longer duration, by never becoming voiced in an otherwise voiceable environment, etc. The utility of syllable in stress rules is well exemplified in such tradiational statements as:

In Czech, stress falls regularly on the first syllable;

In Polish, stress falls regularly on the penultimate syllable;

In French, stress falls regularly on the final syllable.

The same can be said of tones. Typically, the domain of a tone is a syllable, and again, vowels are not the only segments that carry tones. A tone sandhi may appear in such complex forms as inducing nasalization or voicing of the initial consonant in low tone 


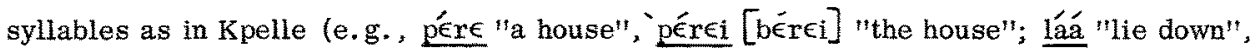
laá [náá] "lay it down". Welmers, 1962), or high tone inducing devoicing or aspiration as happens in some Chinese dialects.

\section{Linguistic Implications}

I will now examine some linguistic implications of the syllable model. Firstly, difficulty in speaking a foreigh language having the same set of sounds (e.g., English and Swahili) or in pronouncing nonsense forms violating the native morpheme structure conditions (e.g., try mpstgli ; it is merely a rearrangement of the word glimpsed by shifting gli to the end) can be explained in terms of this model. That is, it would be naturally difficult to re-program the serial behavior.

Furthermore, if we accept the assumption that the minimal unit of speech production is a syllable, then this assumption dictates that coarticulation and metathesis between segments across a syllable boundary should seldom occur, while they would occur maximally within a syllable. That is, in the string abc \#yz where \# is a syllable boundary, it should be rare for $\underline{b}$ and $y$, or $\underline{a}$ and $\underline{z}$ to be coarticulated or to changes places, while it predicts that coarticulation and metathesis between segments within a syllable would be more com mon. This follows since our peripheral organs would presumably have the information about the whole syllable at the beginning of articulation of the syllable, and one can expect cases where compatible articulations for different segments within a syllable are simultaneously made or where a sequence of segments are realized in a reversed order perhaps due to excessively simultaneous coarticulation. History and children are abound with examples of metathesis, e.g., horse (from hros), bird (from brid), ask - ax, lisp - lips, etc. I will give one more specific example here. In French, nazalization of vowels occurs only before a tautosyllabic nasal, but not before a nasal that constitutes the initial segment of the next syllable, e.g., langage [lagaĵ] "language" but lanice lanis "woolen". Why should this be so? The lowering of the velum in anticipation of the following nasal should occur irrespective of the position of the syllable break. The syllable theory would explain a nasal coarticulation in a tautosyllabic VN and its absence across a syllable boundary in a natural way.

Consider now the assumption which has been favored here in connection with a familiar phonological rule of the form:

$$
\mathrm{X} \rightarrow \mathrm{Y} /+\ldots
$$

If one cherishes a chain-association model (a model that explains a serial behavior $\mathrm{ABC}$ as $\mathrm{A}$ eliciting $\mathrm{B}$ response which then becomes a stimulus for $\mathrm{C}$ response, and so on), then it seems to me that he cannot write such a rule, for how can he explain that what follows (Z) triggers a change in what precedes ( $X$ to $Y$ ), when at the same time one is about to 
accomplish the required adjustment, one has no information at all about $Z$ as $Z$ has to wait for the completion of $\mathrm{X}$ ? In view of the fact that there are rarely context-free rules, but that many phonological rules are context-restricted, like the above, necessitating the specification of such units as syllables or stress groups as the domain in which a change is triggered, one can only wonder what the phonological rules would look like and how many "exceptions" and "environments" one could dispense with if rules were written in terms of the motor units. It is known, for example, that Verner's Law and consonant clusters are exceptions to Grimm's Law. As Ladefoged (1967, p. 172) speculates, if all $\mathrm{t}^{\prime} \mathrm{s}$ were the same in the sense that all $\underline{t}^{\prime}$ 's had the same storage pattern and the same neural coding in the brain, then shouldn't all t's have changed in the same way without exception? But once we accept the assumption that each $t$ had a different neural representation depending upon the syllabic structure of which it is a part, then exceptions may cease to be exceptions.

This gives more magnitude to the status of syllable as a linguistic unit. Indeed, in phonological rules there are some constraints that seem to be due to the nature of the syllable as a unit. For example, one can imagine rules that state: "shift the stress to the next syllable", "lengthen a vowel in every second syllable" (e.g., in Tübatulabal, a UtoAztecan in Cali fornia, ta:Wəgi:nana:la "go along causing him to see"), or "destress in front of a stressed syllable", etc., but hardly such rules as "shift the stress to the next segment", "lengthen every second segment", etc.

\section{Syllabic Property}

Having deposed segment for syllable, one might ask what the exact nature of syllable is, as I have been using the term in a rather loose way. Unfortunately, despite the fact that most layment can intuitively determine the correct number of syllables within a word, we don't know yet exactly what a syllable is. Stetson's (1951) theory that each syllable is accompanied by a "ballistic chest pulse" has been refuted by Ladefoged (1962), and phoneticians are still unable to find simply physiological correlates of syllables. It seems that a syllable as a unit must have some minumum requirements. This requirement may be in terms of a certain number of segments, morae, or a certain amount of muscle work. English monosyllabic words, for example, must contain a tense vowel, e.g., he, how, eye, may, boy, etc., or must end in a consonant if the vowel is lax, e.g. , hid, at, met, us, bed, etc.

It is appropriate at this point to examine another example that Sapir (1933) gives as evidence of the psychological reality of phonemes. Sapir noticed that in his phonetics classes his students had an illusion of hearing a final glottal stop in such dictated nonsense words as sme, or pilá, but not in the case of pila or pilá:. Noting, as we did in the preceding paragraph, that an accented final syllable in English must end in a tense (long) vowel 
with or without a following consonant, or in a short vowel that must be followed by a consonent or a consonant cluster, Sapir writes that "the illusion of the final glottal stop is essentially the illusion of a generalized final consonant needed to classify the dictated words into a known category". In what sense, then, does the illusion of hearing the word-final ? constitute an evidence of the psychological reality of phonemes? ? is not even an English phoneme, nor is it an allophone of a particular consonant in the word-final position (it may occur as an allophone of $t$ in such words as captain $[\mathrm{kaep} ? \mathrm{~m}]$, mountain [maun ? $\mathrm{n}$ ], bottle [bo?l], etc.). Isn't it more reasonable and plausible to say that the illusion is due to the psychological reality of syllables whose constituents must meet some minimum requirements in English? When one considers the fact that the illusion of ? did not happen in the case of syllables that met such requirements, it becomes clear that the ?illusion is not to be explained on a segmental level but within the frame of a syllable.

The so-called "compensatory lengthening" of a vowel in the environment of a consonental loss (e.g., Late OE nyht $\rightarrow M E$ nít "night", PIE nisdos $\rightarrow$ Lat. nīdus "nest", PGmc. gans $\rightarrow O E$ gōs "goose"), or a consonant gemination ensuing a vowel loss or shortening (e.g., Lat. vïdere "see": PP. visus, but sedere "sit": PP. sessus) is also, I feel, functionally related to the effort to preserve the unity of a syllable.

Kozhevnikov and Chistovich have advanced the notion that any number of prevocalic consonants forms a syllable-unit with the following vowel (the final postvocalic consonant is said to constitute a syllable of its own). Later, they suggest that the simplest and the most basic articulatory unit is the consonant-vowel syllable complex, and that more complex $\mathrm{c}$ combinations of the type CCV are nothing but the groups of these simple complexs organized in such a way that the second complex is accomplished partially in parallel with the accomplishment of the first, supporting Fairbanks and Guttman's (1958) conclusion that multiple repetitions of a complex of movements which formally coincide with a $\mathrm{CV}$ syllable are very typical for artificial stuttering.

Can we say that $\mathrm{CCV}=\mathrm{CX}+\mathrm{CV}$ where $\mathrm{X}$ is a vowel reflex? It is certainly tempting to think that all syllables are of a simple CV type. There are certain indications that this might be a proto-type. Many languages have cimple CVCV sequences (e.g., Japanese, Swahili, Yoruba), and linguistic changes seem to favor those whose output is closer to the optimum sequence CVCV (it is achieved, for example, by breaking up consonant clusters, by epentheszing vowels, etc.) CVCV sequences are also children's favorite vocabulary, e.g., mommy, daddy, doggie, chickie, etc. Forms like mom, dad, dog, etc. are certainly later developments.

The distinction between a "weak" syllable and a "strong" syllable in English stress rules (Chomsky and Halle, 1968, p. 29) is interesting to examine in this respect. For 
example, both words PERson and DIAlect have the stress in the initial syllable, but when the affix -al is added, the stress remains on the first syllable in PERsonal but shifts to the next syllable in DLAlect to give diaLECTal. The reason is of course given as being due to the different syllable structures of the penultimate syllable, -son- being a "weak" syllable, while -lect- being a "strong" syllable. But if we assume that the consonant cluster in lect has an intervening vowel reflex (which is deleted after the stress rule), both forms would have the stress on the antepenultimate syllable. Admittedly, this is a wild speculation, "but I think it is worth having a fresh look at all phonological behavior, especially the prosody and exceptions, with the theory of sullable integrated into the current theory.

Recently, MacKay (1971) proposed that the encoding of the syllable of the type CVC be made in two stages:

1. $\mathrm{S}($ yllable $) \rightarrow \mathrm{CP}+\mathrm{VP} \quad \mathrm{CP}=$ consonant part, $\mathrm{VP}=$ vocalic part

2. $\mathrm{VP} \rightarrow \mathrm{V}$ (owel) $+\mathrm{CP}$

(I cannot help but notice the parallelism between the above and Chomsky's well-known generative rules: $s \rightarrow N P+V P, V P \rightarrow V+N P !)$. As evidence for justifying the primary break between $\mathrm{C}$ and VC rather than between $\mathrm{CV}$ and $\mathrm{C}$, MacKay cites rhyme in poetry (e.g., h/old, t/old, g/old), P/ig L/atin (ig-p-ay atin-l-ay), and spoonerisms (e.g., shell $=$ sh(out $)+(y)$ ell). (I may add here alliteration, e.g., w/ild and w/ooly, as another supporting phenomenon.) In the light of evidence cited, I find MacKay's postulation of syllabic property and encoding procedure very appealing and interesting.

\section{Concluding Remarks}

In this paper, I have discussed a few specific models of speech production. I have also examined some speech phenomena that seem to indicate the utility of the syllable as a model of linguistic performance. While such indications are quite a few in number, as we have seen, one must guard oneself against undue optimism in the absence of any cortical evidence, and against unwarranted impudence, the sort that shrouded the phoneme for decades. Chronologically, the syllable theory may have been adopted, as the phoneme began to lose its explanatory power, simply as a cautious measure, as the immediately next phonological unit larger than a phoneme is a syllable. This is to say that what seems to be certain is not so much that the syllable is the (minimal) unit of speech production as that the phoneme is too small a unit. Thus, there is no reason why one may not speculate on some other unit than a syllable. Indeed, there are a few signs that point to the word as a plausible unit. For example, a temporal compensation in Slovak and Estonian operates intersyllabically as well as intrasyllabically (i.e., the structure of a preceding syllable determines the vowel length of the following syllable, cf. Lehiste, 1965). Also, the examples from Lehiste (1970) that I cited earlier fit a word model better than a syllable model. And the domain of 
most phonological rules, e.g. , vowel harmony, stress, etc. is the word, that is, they operate only within the word boundary (hence the term, word-level phonology). Spoonerism is another example where association jumps across a syllable boundary, sometimes a word boundary, although there is a constraint in such a way that a switching takes place only between segments that occupy the same position in syllabic structure, i.e., only between syllable initials, syllabic nuclei, or between the post-nuclei segments in two syllables (cf. Fromkin, 1971; MacKay, 1970).

Even if the syllable theory proves to be correct, there still remains a major task of defining the syllable at a neuro-muscular level and of specifying its exact role as an explanatory tool in phonetic and phonological descriptions. Linguists, who are essentially nonexperimentalists, like to describe syllables in terms of language-specific surface constraints on phonemic strings (the so-called morpheme structure conditions). Since these constraints differ from language to language, does this mean that each language has differently sized units of neural commands? Perhaps so, although one would like to think that neural mechanisms are basically the same for all men. Also, in the case of speech rhythm, what does it mean to say that a language is syllable-timed, while another is stress-timed? Exactly, how does the relationship between rhythm and syllable differ in these two types of languages?

Another problem is the question of the syllable at two leve of description: phonological (deep, linguistics) and phonetic (surface physiological). Is the syllable definable at both levels or only at one of the two? If the latter, which one? Could it be, for example, that syllables are units only at the physiological level, while the units at the linguistic level are segments? If so, just what is the relationship between the two? (cf. Tatham, 1971.)

Needless to say, resolution of these questions will have to wait further study and neurophysiological evidence. As the new wave of phonetics sails from the tongue to the brain (cf. Kim, 1971a), it should find such evidence hovering offshore, if not in the offing. Meanwhile, I suppose one is allowed to play the role of either a defense lawyer or a prosecuting attorney disputing about circumstantial evidence. Personally, I find it difficult to believe that the command sequence for the word yes is just the reverse of that for the word say, sey. Somehow, I feel that their storage and retrieval in the brain is unitary, independent, and free of segmental association.

\section{References}

Boomer, D.S. and J.D.M. Laver (1968), "Slips of the Tongue", British Journal of Disorders of Communication, $3,1-12$.

Chomsky, N. and M. Halle (1968), The Sound Pattern of English, Harper and Row, New York. Daniloff, R. and K. Moll (1968), "Coarticulation in Lip Rounding", Journal of Speech and Hearing Research, 11, 707-721. 
Fairbanks, G. (1954), "A Theory of the Speech Mechanism as a Servo-System", Journal of Speech and Hearing Disorders, 19, 133-139.

Fairbanks, G. and N. Guttman (1958), "Effects of Delayed Auditory Feedback upon Articulation", Journal of Speech and Hearing Research, $1,12-22$.

Fromkin, Victoria (1965), "Some Phonetic Specifications of Linguistic Units: An Electromyographic Investigation", UCLA Working Papers in Phonetics, No. 3.

Fromkin, Victoria (1966), "Neuromuscular Specification of Linguistic Units", Language and Speech, 9, 170-199.

Fromkin, Victoria (1968), "Speculations on Performance Models", Journal of Linguistics, $\underline{4}, 47-68$.

Fromkin , Victoria (1971), "The Non-Anomalous Nature of Anomalous Utterances", Language, 47, 27-52.

Fry, D. B. (1964), "The Functions of the Syllable", Zeitschrift fur Phonetik, 17, 215-237.

Halle, M. and K.N. Stevens (1964), "Speech Recognition: A Model and a Program for Research", in Fodor and Katz (eds.). The Structure of Language, Prentice-Hall, 604-612.

Harris, Katherine, S., G. F. Lysaught, and M.M. Schvey (1965), "Some Aspects of the Production of Oral and Nasal Labial Stops", Language and Speech, $8,135-147$.

Hebb, D. O. (1949), "The Organization of Behavior, Wiley, New York.

Hockett, C.F. (1967), "Where the Tongue Slips, There Slip I", in To Honor Roman Jakobson, Vol, II, Mouton, The Hague, 910-936.

Jones, D. (1959), An Outline of English Phonetics, 8th ed., E.P. Dutton, New York.

Kim, C-W (1971a), "A New Direction in Phonetics", Language Sciences, 16, 35-40.

Kim, C-W (1971b), "Experimental Phonetics", in W. O. Dingwal (ed.), A Survey of Linguistic Science, University of Maryland Press, 16-128.

Kozhevnikov, V.A. and L.A. Chistovich (1965), Rech: Artikulatsia i Vosprovatiye, MoskvaLeningrad. English Translation by Joint Publications Research Service, U.S. Department of Commerce, Speech: Articulation and Perception (1966).

Ladefoged, P. (1962), "Sub-glottal Activity During Speech", Proceedings of the IVth International Congress of Phonetic Sciences, Mouton, The Hague, 73-91.

Ladefoged, P. (1967), "Units in the Perception and Production of Speech", in his Three Areas of Experimental Phonetics, 143-172.

Lashley, K.S. (1951), "The Problem of Serial Order in Behavior", in L. A. Jeffress (ed.), Cerebral Mechanisms in Behavior, Wiley, 112-136. Reprinted in Saporta (ed.), Psycholinguistics, 180-198.

Lehiste, Ilse (1965), "The Function of Quantity in Finnish and Estonian", Language, 41, $447-456$.

Lehiste, IIse (1970), "Temporal Organization of Spoken Language", Ohio State Univer sity Working Papers in Linguistics, $\underline{4}, 95-114$.

Lenneberg, E.H. (1967), Biological Foundations of Language, Wiley, New York.

Lindblom, B. (1968), "Temporal Organization of Syllable Production", Quarterly Progress and Status Report, 1968.2/3:1-5, Speech Transmission Laboratory, Royal Institute of Technology, Stockholm. 
Lubkex, J.P. and Pamela J. Parris (1970), "Simultaneous Measurement of Intraoral Pressure, Force of Labial Contact, and Labial Electromyographic Activity During Production of the Stop Consonant Cognates $/ p /$ and $/ b / "$, Journal of Acoustic Society of America, 47, 725-633.

MacKay, D.G. (1970), "Spoonerisms: The Structure of Errors in the Serial Order of Speech", Neuropsychologia, $8,323-350$.

Mackay, D.G. (1971), "The Structure of Words and Syllables: Evidence from Errors in Speech, MS.

MacNeilage, P.F. (1963), "Electromyographic and Acoustic Study of the Production of Certain Final Clusters", Journal of Acoustic Society of America, 35, 461-463.

MacNeilage, P.F. (1970), "Motor Control of Serial Ordering of Speech", Psychological Review, 77, 182-196.

MacNeilage, P.F. and G.N. Sholes (1964), "An Electrom ographic Study of the Tongue During Vowel Production", Journal of Speech and Hearing Research, 7, 209-232.

Ohala, J. (1970), "Aspects of the Control and Production of Speech", UCLA Working Papers in Phonetics, No. 15.

Ohman, S. (1967), "Peripheral Motor Commands in Labial Articulation", Quarterly Progress and Status Peport, 1967.4:30-63, Speech Transmission Laboratory, Royal Institute of Technology, Stockholm.

Rozin, P., Susan Poritsky, and Raina Sotsky (1971), "American Children with Reading Problems can Easily Learn to Read English Represented by Chinese Characters", Science, 171, 1264-1267.

Sapir, E. (1933), "La realite psychologique des phonemes", Journal de Psychologie, 30 , 247-265. (English translation in D.G. Mandelbaum (ed.), Selected Writing of Edward Sapir, University of California Press (1963), 46-60.

Stetson, R.H. (1951), Motor Phonetics, North Holland Publishing Co., Amsterdam.

Tatham, M.A.A. (1971), "Motor Building in Phonetic Theory", Language Sciences, 14, $16-19$.

Tatham, M. A.A. and Katherine Morton (1969), "Some Electromyography Data Towards a Model of Speech Production", Language and Speech, 12, 39-53.

Tatham, M.A.A. and Katherine Morton (1970), "Explaining Some Apparently ContextSensitive Effects in Speech", University of Essex Language Center Occasional Papers, g. $116-122$.

Taylor, I.K. (1966), "What Words are Stuttered?" Psychological Bulletin, 65, 236-242.

Thomas, I. B. and P.B. Hill, F.S. Carrol, and B. Garcia (1970), "Temporal Order in the Perception of Vowels", Journal of Acoustic Society of America, 48, 1010-1013.

Welmers, W.E. (1962), "The Phonology of Kpelle", Journal of African Languages, 1, 69-93.

Whitaker, H.A. (1970), "Some Constraints on Speech Production Models", University of Essex Language Occasional Papers, 9, 1-13.

Wickelgren, W.A. (1969), "Context-Sensitive Coding, Associative Memory, and Serial Order in (Speech) Behavior", Psychological Review, 76, 1-15. 